\title{
Analise histórica da frequência de ocorrência de incêndios florestais no município de Linhares, Espírito Santo
}

\author{
Felipe Patrício das Neves ${ }^{1}$, Nilton César Fiedler ${ }^{*}$, Weslen Pintor Canzian ${ }^{2}$
}

\begin{abstract}
Resumo: Estudos sobre a série histórica de atendimentos a incêndios florestais por bombeiros militares são muito importantes, devido ao aumento da frequência de ocorrências e dos danos econômicos, sociais e ambientais. Esta pesquisa teve como objetivo descrever o comportamento e a periodicidade de ocorrências de incêndios florestais no município de Linhares, estado do Espírito Santo, destacando fases de maior incidência, bem como regiões mais castigadas. Utilizaramse registros de atendimentos do Corpo de Bombeiros Militar, de 2015 a 2019. Além da análise de dados, utilizou-se o software QGIS, para análises espaciais. No período foram registrados 1.029 ocorrências, destacando-se os bairros Canivete $(8,45 \%)$, Bebedouro (6,8\%), Planalto (5,25\%), Três Barras (4,86\%), além de Movelar e Rio Quartel (4,28\%). As ocorrências na zona rural se destacaram (22,35\%). A maior periodicidade ocorreu nas estações do verão $(30,17 \%)$ e primavera (25,33\%). Mapas de calor anuais, com o interpolador de Kernel, destacando concentração de incêndios, indicaram novas regiões de densidade distribuídas também no interior do município. Observou-se que 2015 e 2019 foram os anos mais críticos do período analisado. Concluiu-se que os resultados forneceram aos gestores informações muito importantes, capazes de tornar mais eficazes as atividades de controle, prevenção e fiscalização de incêndios florestais.
\end{abstract} Palavras-chave: controle de incêndios, gestão florestal, prevenção.

\section{Historical analysis of the occurrence of forest fires in the municipality of Linhares, Espírito Santo}

\begin{abstract}
Studies on the historical series of assistance to forest fires by military firefighters are very important, due to the increased frequency of occurrences and economic, social and environmental damage. This research aimed to describe the behavior and frequency of occurrences of forest fires in the municipality of Linhares, state of Espírito Santo, highlighting phases of higher incidence, as well as more punished regions. Records of assistance from the Military Fire Department were used, from 2015 to 2019. In addition to data analysis, the QGIS software was used for spatial analysis. In the period, 1,029 occurrences were registered, highlighting the neighborhoods Canivete $(8.45 \%)$, Bebedouro $(6.8 \%)$, Planalto (5.25\%), Três Barras (4.86\%), in addition to Movelar and Rio Barracks (4.28\%). Occurrences in the rural area stood out $(22.35 \%)$. The highest periodicity occurred in the summer $(30.17 \%)$ and spring $(25.33 \%)$ seasons. Annual heat maps, with the Kernel interpolator, highlighting the concentration of fires, indicated new regions of density also distributed in the interior of the municipality. It was observed that 2015 and 2019 were the most critical years of the analyzed period. It was concluded that the results provided managers with very important information, capable of making forest fire control, prevention and inspection activities more effective.
\end{abstract}

Keywords: fire control, forest management, prevention.

\section{INTRODUÇÃO}

Os incêndios florestais têm trazido inúmeros prejuízos financeiros, à saúde da população e ao meio ambiente, tanto no estado do Espirito Santo, quanto no país e no mundo. Estudos sobre a série histórica de atendimentos de bombeiros militares a incêndios florestais são muito importantes, por este fenômeno ser cada vez mais frequente, pela necessidade de meios economicamente viáveis de controle e pela preservação ambiental.

Tem-se como exemplos de consequências o aquecimento do solo e redução de seus nutrientes, a erosão, alteração do microclima, redução do teor de matéria orgânica e acidez do solo, comprometimento da qualidade da água, ameaças à fauna, à qualidade da madeira, impactos agrícolas e prejuízos à população (FIEDLER, 2006; GUIMARÃES et al.,
2014; HERAWATI; SANTOSO, 2011; SOARES; BATISTA, 2007).

Para Gobbo et al. (2016), os incêndios florestais são realidade no mundo inteiro. Além disso, em relação a todo o continente, as maiores médias por ano tanto em número de incêndios quanto também por áreas queimadas, encontram-se na América do Sul (SILVA, 2018). Consomem de maneira geral anualmente milhares de hectares de florestas em todo mundo, provocando efeitos de grande impacto, tanto do ponto de vista econômico como ambiental e social (BATISTA, 2009).

Esses dados são bastante alarmantes para todos e a Administração Pública não pode se omitir em adotar providências para a solução de tal problema. O setor público deve prestar um serviço mais eficiente e eficaz à sociedade, incentivando para isso a modernização de suas agências (CAEMMERER;

Recebido em 05/12/2020; Aceito para publicação em 26/02/2021

${ }^{1}$ Universidade Federal do Espírito Santo

${ }^{2}$ Suzano S.A.

*email: fiedler@pq.cnpq.br 
WILSON, 2011). Vários países têm investido cada vez mais em proteção, prevenção e investigação de incêndios (MAINARDES; CERQUEIRA; VASSOLER, 2016).

Portanto, a Administração Pública contemporânea tem buscado há bastante tempo alternativas para aperfeiçoar o serviço público oferecido à sociedade, modernizando-se constantemente, e este estudo é uma iniciativa, na busca por maior eficiência das ações de combate aos incêndios florestais.

Os custos de atendimento a grandes incêndios florestais no país são enormes. Portanto, o presente estudo é muito importante justamente no sentido de levantar informações para construção de estratégias economicamente viáveis, garantindo proteção da riqueza ambiental do Brasil, com a adoção de ações mais otimizadas e eficientes.

Contar com dados históricos e um bom índice de previsão facilitam a construção de políticas voltadas para a quantificação e distribuição dos recursos de prevenção, visando à redução de perdas e, assim também de prejuízos ambientais e financeiros (PEREIRA et al., 2012; TORRES et al., 2017).

\section{MATERIAIS E MÉTODOS}

A área de estudo compreende o território do município de Linhares, no estado do Espirito Santo, localizado na região Sudeste do Brasil (19 $23^{\circ}$ '28' ' de latitude Sul e 4004'20', longitude Oeste de Greenwich, e área total de $3.504 \mathrm{~km}^{2}$ ), conforme a Figura 1.

Figura 1 - Área de estudo.

Fonte: Elaborado pelos autores.

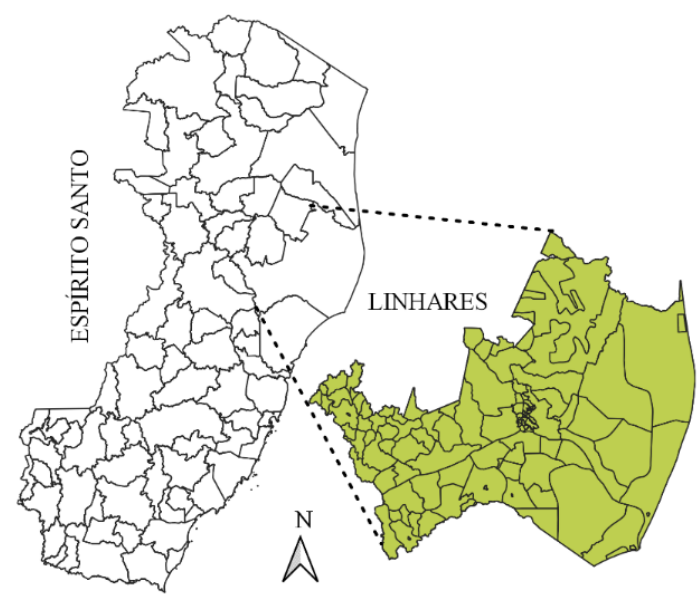

\section{Dados}

Foram utilizados registros de incêndios florestais do Centro Integrado Operacional de Defesa Social (CIODES), da Secretaria Estadual de Segurança Pública e Defesa Social (SESP), de atendimentos realizados pelo Corpo de Bombeiros Militar do Estado do Espírito Santo (CBMES), entre os anos de 2015 a 2019. Além disso, para análise espacial e identificação das áreas de maior criticidade, foram utilizados mapas do Sistema Integrado de Bases Geoespaciais do Estado do Espírito Santo (GEOBASES).

\section{Metodologia}

Utilizando o software de geoprocessamento livre QGIS, versão 3.16, pretendeu-se estabelecer os 05 bairros que apresentaram maior incidência, servindo de sugestão de locais a serem priorizados para ações preventivas e estratégias de fiscalização e combate. Além disso, analisando a disposição mensal dos dados, foi possível notar as estações do ano de maior criticidade, e assim estabelecer as fases prévias de planejamento e preparação. Na Figura 2 a seguir, encontra-se o fluxograma metodológico utilizado neste estudo, que descreve de forma objetiva as etapas adotadas, para, enfim, tomada de decisão por parte dos gestores responsáveis. Para obtenção dos mapas de calor, utilizou-se o cálculo de densidade de Kernel, por meio de técnicas de geoprocessamento (SILVERMAN, 1983). As manchas obtidas nos mapas, que vão da coloração azul à vermelha, destacam o grau de concentração de incêndios florestais, bem como seu raio de influência na região, representada por uma função matemática, geralmente do tipo gaussiana, conforme Figura 3. 


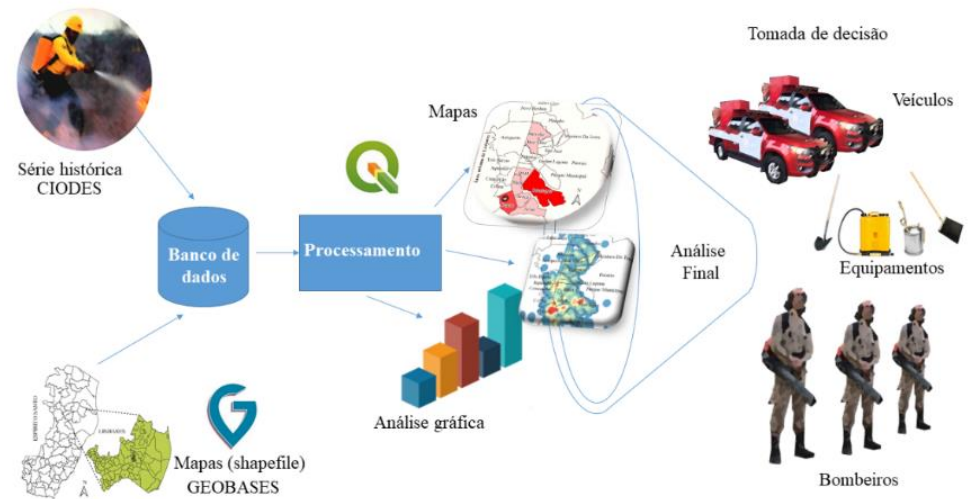

Figura 2 - Fluxograma metodológico.

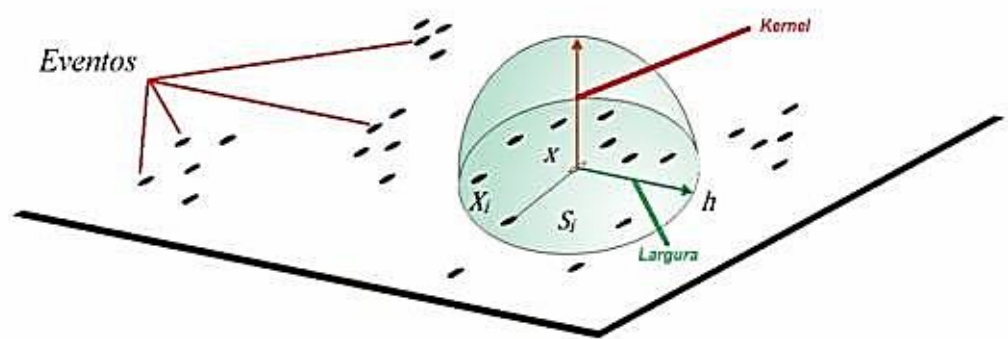

Figura 3 - Densidade de Kernel.

Fonte: De Oliveira, Brito e De Oliveira (2019).

\section{RESULTADOS E DISCUSSÃO}

Como resultados da pesquisa, registraram-se 1.029 atendimentos, destacando-se os bairros Canivete $(8,45 \%)$, Bebedouro $(6,8 \%)$, Planalto
(5,25\%), Três Barras (4,86\%), além de Movelar e Rio Quartel (4,28\%), conforme Mapa Coroplético (Temático), na Figura 4.

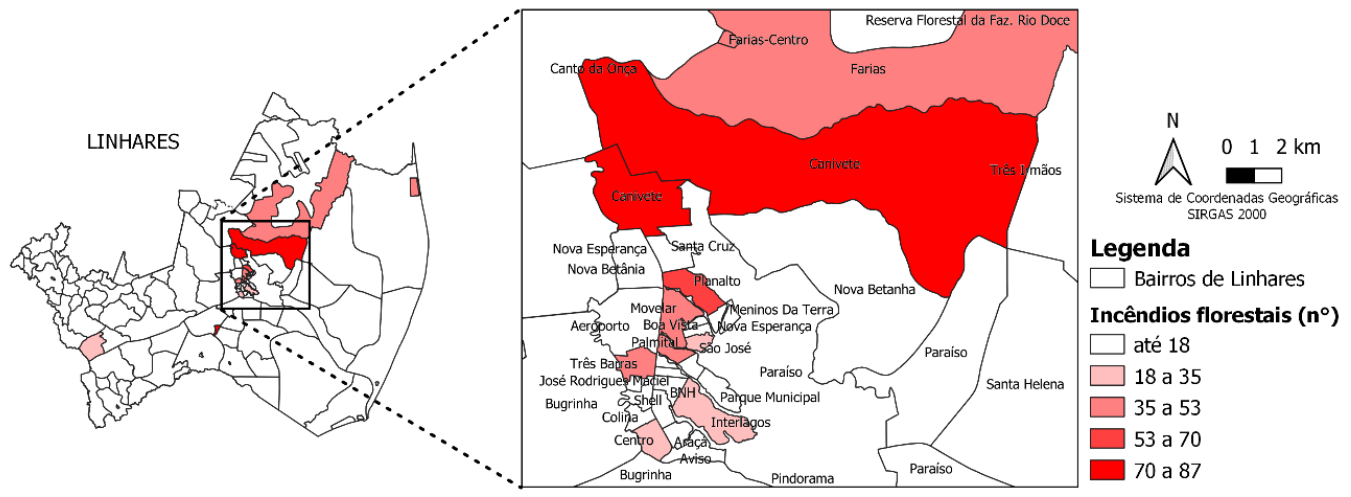

Figura 4 - Mapa Coroplético.

Fonte: Elaborado pelos autores.

Nas áreas rurais também ocorreram grande número de registros $(22,35 \%)$. Assim, infere-se que é muito importante dispor de veículos capazes de transitar em diversos tipos de terreno e com grande alcance de combate, com linhas de mangueira ou mangote atingindo longas distâncias e projeção de água.

Destacaram-se as estações do ano como períodos mais críticos o verão (dezembro a março), com
$30,17 \%$, e a primavera (setembro a dezembro), com $25,33 \%$. Mapas de calor anuais, utilizando a ferramenta interpolador estimativa de densidade de Kernel, indicaram surgimento de novas regiões de densidade também pelo interior do município. Para isso foi necessária a geocodificação (obtenção de coordenadas geográficas de latitude e longitude) dos endereços registrados nas ocorrências atendidas pelos bombeiros militares. 

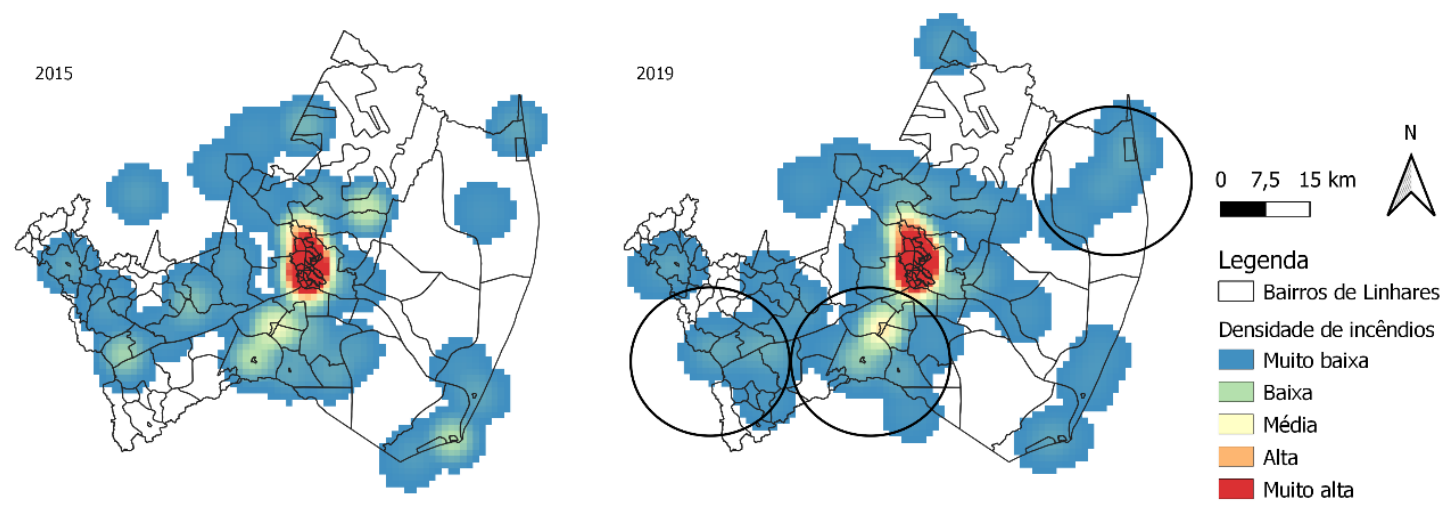

Figura 5 - Mapas de calor de 2015 e 2019 (Linhares/ES) Fonte: Elaborado pelos autores.

Durante o período analisado, foi possível observar que o maior número e distribuição de incêndios no município se deu nos anos de 2015 e 2019, destacando-se neste último ano, além da área urbana central (frequente em todos os anos), as regiões sul, sudoeste e nordeste.

\section{CONCLUSÕES}

A descrição do perfil dos atendimentos, bem como as análises espaciais propostas neste estudo forneceram aos gestores informações de extrema relevância.

As informações obtidas são capazes de potencializar a atividade de prevenção antecipada e controle dos incêndios florestais, com fiscalizações e combate na região em estudo.

Além disso, o estudo em si apresenta metodologia válida e útil para novas áreas e naturezas de ocorrências.

\section{Referências Bibliográficas}

BATISTA, A. C. O uso dos retardantes no combate aéreo aos incêndios florestais. Floresta, v. 39, p. 5-10, 2009.

CAEMMERER, B.; WILSON, A. An exploration of the service orientation discrepancy phenomenon in a public sector context. The Service Industries Journal, v. 31, n. 3, p. 355-370, 2011.

DE OLIVEIRA, A. M.; BRITO, C. A. O.; DE OLIVEIRA, L. N. A. Análise da distribuição espacial urbana das unidades de saúde da família e unidade básica de saúde em feira de Santana. Brazilian Journal of Development, v. 5, n. 7, p. 8534-8543, 2019.

FIEDLER, N. C.; RODRIGUES, T. O.; MEDEIROS, M. B. Avaliação das condições de trabalho, treinamento, saúde e segurança de brigadistas de combate a incêndios florestais em unidades de conservação do Distrito Federal: estudo de caso. Revista Árvore, v.30, n.1, p.55-63, 2006. preocupação com os incêndios florestais. Floresta e Ambiente, v.23, n.3, p.350-361, 2016.

GUIMARÃES, P. P. et al. Análise dos impactos ambientais de um incêndio florestal. Agrarian Academy, v. 1, n. 1, p. 38, 2014.

HERAWATI, H.; SANTOSO, H. Tropical forest susceptibility to and risk of fire under changing climate: A review of fire nature, policy and institutions in Indonesia. Forest Policy and Economics, v. 13, n. 4, p. 227-233, 2011.

MAINARDES, E. W.; CERQUEIRA, A. dos S.; VASSOLER, H. Simplification and Digitalization Practices on Fire Inspection Service: Case Study in a State Fire Department in Brazil. Applying Quality of Life Research. 1ed.: Springer International Publishing, 2016, p. 203-215.

PEREIRA, A. A. et al. Validação de focos de calor utilizados no monitoramento orbital. Cerne, v.18, n.2, p.335-343, 2012.

SILVA, E. C. G. et al. Análise temporal da ocorrência de incêndios florestais nas Américas e região do Caribe. Nativa, v. 6, p. 491-496, 2018.

SILVERMAN, B. Density Estimation for Statistics and Data Analysis. Monographs on Statistics and Applied Probability, Chapman and Hall, Londres, 1986.

SOARES, R. V., BATISTA, A. C. Incêndios florestais: controle, efeitos e uso do fogo. Curitiba, 2007. 264 p.

TORRES, F. P. T. et al. Analysis of efficiency of $\mathrm{f}$ ire danger indices in forest fire prediction. Revista Árvore, $v$. 41, n.2, 2017.

GOBBO, S. D. A.; GARCIA, R. F.; AMARAL, A. A.; EUGÊNIO, F. C.; ALVAREZ, C. R. S.; LUPPI, A. S. L. Uso da Terra no entorno do PARNA-Caparaó: 